\title{
Population Growth and Economic Development in Developing and Developed Countries
}

\author{
Mohd Khairul Amri Kamarudin 1,2*, Noorjima Abd Wahab ${ }^{2}$, Mahadzirah Mohamad ${ }^{3}$, Ahmad Shakir Mohd Saudi ${ }^{4}$, \\ Mohamad Shaharudin Samsurijan ${ }^{5}$, Muhammad Hafiz Md. Saad ${ }^{2,6}$, Siti Nuratiqah Yusri', Nurwahidatul Aula Ah- \\ mad Sazali ${ }^{1}$, Nur Fadhlina Afiqah Abdul Latif ${ }^{1}$, Siti Norsyafawati Abdul Rahim¹, Nurul Najiha Syuhada Samsur- \\ ing ${ }^{1}$ \\ ${ }^{1}$ Faculty of Applied Social Science, Universiti Sultan Zainal Abidin, Gong Badak Campus, 21300 Kuala Nerus, Terengganu, Malaysia \\ ${ }^{2}$ East Coast Environmental Research Institute (ESERI), Universiti Sultan Zainal Abidin, Gong Badak Campus, 21300 Kuala Nerus, Ter- \\ engganu, Malaysia \\ ${ }^{3}$ Faculty of Economics and Management Science, Universiti Sultan Zainal Abidin, Kuala Gong Badak Campus, 21300 Kuala Nerus, \\ Malaysia \\ ${ }^{4}$ Department of Environmental Health, Institute of Medical Science Technology Universiti Kuala Lumpur, Kajang, Selangor, Malaysia \\ ${ }^{5}$ Pusat Pengajian Sains Kemasyarakatan,Universiti Sains Malaysia, 11800 USM ,Pulau Pinang, Malaysia \\ ${ }^{6}$ AB Bakti Enterprise, Lot 27215 Kg. Gong Kuin 2, Jalan Tok Jembal, 21300 Kuala Nerus, Terengganu, Malaysia \\ *Corresponding authorE-mail: mkhairulamri@unisza.edu.my
}

\begin{abstract}
This research examines the effects of population growth on the economic development between the two developed and developing countries which is Singapore and Malaysia. They were many previous studies that have sought to gauge the effects or impact of population growth along the economic development. It was said that there was a strong relationship between the effects of population growth and the economic development, which is the growth of population is depending on the economic growth. Singapore was well known worldwide as a highly developed free-market economy. The economy of Singapore has been ranked as the most open in the world and the most-pro business. The population in the country is estimated at 5.5 million recently. As for Malaysia, it is known as the most competitive developing countries and is ranked on the 5th largest in South Asia. The population estimated at 31.63 million in Malaysia.
\end{abstract}

Keywords: Economy; populations; percentage; developed country; developing country.

\section{Introduction}

The economists from the world have often neglected the impact of population dynamics on economic growth in the developing and developed countries. In [1] are among the few who explore the effect of the population dynamics on economic growth. They argue that it is possible that the interaction of economic growth with population dynamics can result in a poverty trap. Developing countries have not been able to achieve the predetermined development goals or have not been able to balance the achievement of development that has been done caused by the population problems or high population growth. It is also an uneven distribution of population high poverty and unemployment and has caused high burden of burden and low per capital income and dominance of primary goods [2].

According [3], the mortality rate decline aids economic growth and hence leads to an increase in the standard of living. As people live longer, they tend to think more about the future and are more likely to take risk and innovate. The developing countries that mortality decline has the tendency to raise educational attainment and savings rates and thus to increase investment in both physical and human capitals. The mortality decline has identified population growth, fertility and age-structural change as well as urban growth/urbanization as demographic factors that affect economic growth. The impact of population dynamics of the various dimensions of the demographic transition on per capita, Gross Domestic Product (GDP) growth in developing and developed countries [46].

Besides that, others study claimed the developing countries that mortality decline has the tendency to raise educational attainment and savings rates and thus to increase investment in both physical and human capitals. Mortality decline is also accompanied by health gains that in turn enhance people's economic productivity. When population grows faster than GNP, the standard of living of the people does not improve. In fact, rapid population growth has been obstructing economic growth in developing countries [7].

In Table 1, we present population growth in India. It will be seen that since 1951, population has been growing at about two per cent or more. In other developing countries such as Pakistan Bangladesh, rate of population has been growing at about two per cent or more. In other developing countries such as Pakistan Bangladesh, rate of population has been greater than that of India. However, it may be noted that over-population and rapid the population rate is especially an Asian problem. The developing countries of Latin America and Africa do not face this population explosion problem. But for developing countries like India, population growth has to be checked if gains of development are not being nullified by it. It is worthwhile to note here that it is only China which has brought population growth rate quite will under control by adopting one 
child per family norm. The existing state of knowledge does not warrant any clear-cut generalization as to the effect of population growth on economic development in today's less developed areas $[8,9]$. Some theoretical analyses argue that high population growth creates pressures on limited natural resources, reduces private and public capital formation, and diverts additions to capital resources to maintaining rather than increasing the stock of capital per worker. Others point to positive effects such as economies of scale and specialization, the possible spur to favorable motivation caused by increased dependency, and the more favorable attitudes, capacities, and motivations of younger populations compared with older ones. The actual evidence on the association between growth rates of population and per capita income does not point to any uniform conclusion, though the true relationship may be obscured in a simple two-variable comparison. None of this means that per capita income growth, currently and in the past, would have been the same if population growth rates had been markedly higher or lower. But, it is possible that the effect of population growth on economic development has been exaggerated, or that no single generalization is justified for countries differing as widely in growth rates, densities, and income levels as do today's less developed areas. Clearly, there is need for more intensive research on the actual experience of nations, currently and in the past $[10,11]$.

Table 1: The population growth in India from 1951 until 2011

\begin{tabular}{|c|c|c|}
\hline Years & $\begin{array}{c}\text { Population } \\
\text { In Millions }\end{array}$ & $\begin{array}{c}\text { Annual Average Growth Rate } \\
\text { (\%) During Decade }\end{array}$ \\
\hline 1951 & 361 & - \\
\hline 1961 & 439 & 1.96 \\
\hline 1971 & 548 & 2.20 \\
\hline 1981 & 683 & 2.22 \\
\hline 1991 & 843 & 2.14 \\
\hline 2001 & 1028 & 1.93 \\
\hline 2011 & 1210 & 1.6 \\
\hline
\end{tabular}

There are two types of population the limited population and the infinite population (infinity). Limited population that has a clear data source limits quantitatively so that it can be counted. While the population is unlimited, the data source cannot be set boundaries so that relative cannot be expressed in the form of sum. Based on the nature of population can be divided into homogeneous populations and heterogeneous populations. Homogeneous population is the source of data whose elements have the same properties so no need to question the amount quantitatively. While, the heterogeneous population is a source of data whose elements have different characteristics or circumstances (varies), so that it needs to set limits both qualitatively and quantitatively.

Developing countries have not been able to achieve the predetermined development goals or have not been able to balance the achievement of development that has been done. Population problems and high population growth. It is also an uneven distribution of population high poverty and unemployment and has caused high burden of burden and low per capita income and dominance of primary goods [12]. Furthermore, the background of farming methods of cultivation and its production is still done using simple tools and technology. In fact, the use of resources that are not optimally utilized as well as developing countries will work with developed countries in exploiting their natural resources. The result of this natural resource will eventually become a commodity of commerce or export because the country has no technology to produce goods from the raw material source. The dependence on developed countries is lacking in capital and technology to advance the country and will depend on developed countries to obtain technology and financial loans.

In addition, financially finite facilities are limited, so that the government cannot afford to provide all the good public amenities for the people as well as other facilities for outside investors. Furthermore, the low level of education of good educational infrastructure for both formal and non-formal education is still limited and inadequate. As a result, there are still many illiterate developing countries living standards of low-income people working in the agricultural sector that are still traditionally employed. The level of education and the low level of knowledge leads to the inability to compete for employment or job opportunities in other sectors low levels of health and have no awareness of the importance of health. It has an inadequate and inadequate health infrastructure that promotes the health of the people in developing countries is still low. Understanding of developed countries is a country that has a high standard of living with an indication that the economy is evenly distributed the use of high technology and has been successful in various fields. The majority of people in developed countries have high literacy skills. The people are well aware of the importance of education. The advance of social development in developed countries cannot be separated from the role of government in providing social security that is useful to protect the public from the risk of job loss. For example, guarantees of pregnancy accidents illness disability and also old age. In developed countries nearly $50 \%$ of the country's gross national income is allocated to provide social services as well as health services. A country can be regarded as a developed country if it has the characteristics such as high population per capita income, the food is good based on their quantity and quality and level of education is good. Its inhabitants work more in the industrial sector than agriculture and the average life span is better and the percentage of illiteracy is lower. Besides that, the export economy does not depend on the primary product, the population is relatively low with low birth rates. Developed countries also well oriented to domestic and foreign trade. Technological advances and economic development are moving fast. Last but not least, developed countries longer to feel independence and have a higher standard of living State capital exceeds demand [13].

\section{Methodology}

Singapore and Malaysia are chosen as developed and developing countries in Asian because Singapore and Malaysia more developed than the surrounding Southeast Asian economies. Besides that, Singapore and Malaysia are successful economic development depends on good governance. There are different kinds of governance models, of which democracy is one. Good governance does not necessarily mean democracy model. In this study, the researchers need to identify the problems and research matter of the study in order to find the correlation between population increase and economic growth. The researchers also need to know the factors that influence the growth of population in developed country compared to the population in developing country. The data obtained from this study are secondary data based on past records, authoritative reference books on population and economy and referral through the internet. In addition, to look at theoretical aspects such as population increase and economic growth the researcher will refer to past journals, papers and related documents. The secondary data were analyzed by using XLStat2014 and SPC XL licensed soft-ware for Microsoft Excel [14-17]. Based on the data that has been analyzed, the researcher needs to know the factors that influence the economic growth. Researchers also need to state the relationship between population increase and economic growth.

\section{Results and Discussion}

Population is the rate of population growth of a region or country within a certain time period expressed as a percentage. Population growth is a change in the number of population both increase and decrease caused by several factors.

\subsection{Descriptive Analysis}

The death increases then the population number will decrease, but if the death rate decreases it will add also the population because the birth rate jumped drastically. Death is the permanent disappearance of the signs of human life. Death is to reduce the popula- 
tion and to calculate the mortality rate is almost the same as the calculation of the birth rate. The number of deaths is strongly influenced by factors supporting death (pro-mortality) and inhibiting factors of death (anti-morality). Birth rate can be quickly due to birth health technology can be quickly due to health technology then automatically increase the population can jump dramatically because of the growing birth rate. Birth is increasing the population. Besides that, the population migration is the movement of people from one place to another. In the mobility of the population, there is an international migration that is a movement of population that passes the boundaries of a country to another country and also the internal migration which is the migration of population dwelling around the territory of one country only. Based on Figure 1 showed the distribution of population growth in Malaysia higher than Singapore from 1996 until 2016.



Fig. 1: The distribution of population growth in Malaysia and Singapore from 1996 until 2016

The main industry sector for Singapore is a free and successful free market economy with its government playing a key role. Singapore has an open realistic and relatively open business environment with corrupt practices with stable prices. Mostly, they export particularly electronics and chemicals and services are the major sources of revenue that allow them to buy raw materials and natural resources they do not own. Thus, Singapore can be said to rely on a further with the purchase of raw materials in trading concept for refinement for the purpose of re-exporting for example wafer manufacturing and oil refineries. Malaysia practices subsistence economy to accommodate the daily needs of the family. The major subsistence economy activities are farming fishing and harvesting forests. Such activities do not require the use of large currencies. Meanwhile, agriculture fisheries livestock forestry and mining sectors are the industry in Malaysia where it is located the first sector category as it involves economic activities in early stage whether it does or does not involve processing activities.

The use of science and technology for Singapore is that they use English as a native language and they use an educational system that emphasizes teaching and learning at school electronic devices the use of Information and Communication Technology (ICT) during the learning process and they use the 'Portal Interactive Mother Language'. The portal contains a variety of learning materials such as video clips audio and interactive ICT materials that can be used directly for teaching and learning purposes including on-line assessment. For Malaysians, they use Bahasa as a native language and they use the Science and Technology capabilities development system (S\&T). Malaysia must have the capacity to develop and co-ordinate the existing S\&T resources in the country to achieve the goal of "making Malaysia a science-based and progressive society an infamous and far-sighted society a society that can not only capitalize on time technology now, but also contributing to the advancement of science and technology civilization in the future". Furthermore, the improvement of education and the skills of the population of Singapore use the education system as much as Malaysia where they practice formal education from kindergarten that is 6 years old and then into elementary school for 6 years. After that, they entered the high school for 5 years and then entered the junior college for 3 years and then entered the university environment.

Population in Singapore has the slowest pace in the last decade. The reason the government tightened the entry of foreign workers in the last 12 months until last June. Singapore's latest Statistics Department report said the city state had a total population of 5.47 million people by the end of June up $1.3 \%$ from a year earlier. The number of Singaporean citizens reached 3.34 million people up $0.9 \%$ from a year earlier. While, the number of permanent residents was down $0.7 \%$ to 527700 people. According to statistics, more than $29 \%$ of Singapore's population consists of non-residents who work study or live in the country but are not granted permanent residency includes permanent residents. Statistics show that the number of foreigners accounts for nearly $40 \%$ of Singapore's total population. In 2017, in Malaysia, the male population remains the same above the female population. The sex ratio for the 2016-2017 period stay stills at 107 men per 100 women. The sex ratio of citizens and non-citizens also remains at 102 and 157 for the same period. Percentage of people aged 0-14 years in 2017 declines to $24.1 \%$ measured to $24.5 \%$ in 2016 . While, the percentage of 15-64 years old population expands from $69.5 \%$ in 2016 to $69.7 \%$ in 2017 . The increase in population in this age group has a direct impact on increase in intermediate age in 2017 (28.3 years). The Bumiputera ethnic indicates a rise in the size of 0.2 percentage points measured to 2016 , which is 68.8 per cent of the total population of citizens. However, Chinese ethnicity registered a decrease of 0.2 percentage points to $23.2 \%$ while the Indian and Others ethnic groups remained at $7.0 \%$ and $1.0 \%$ respectively as compared to 2016. Based on Figure 2, in 1998, the population in Malaysia was 22113464 million while economic growth decreased $-7.36 \%$. In Singapore, the population is 5778706 million while the economic growth decreases $-2.23 \%$. The population in Malaysia in 1996 was 21023321 million, while economic growth increased by $10 \%$. In Singapore, in 2010, the population was 6164626 million while economic growth increased by $15.24 \%$.

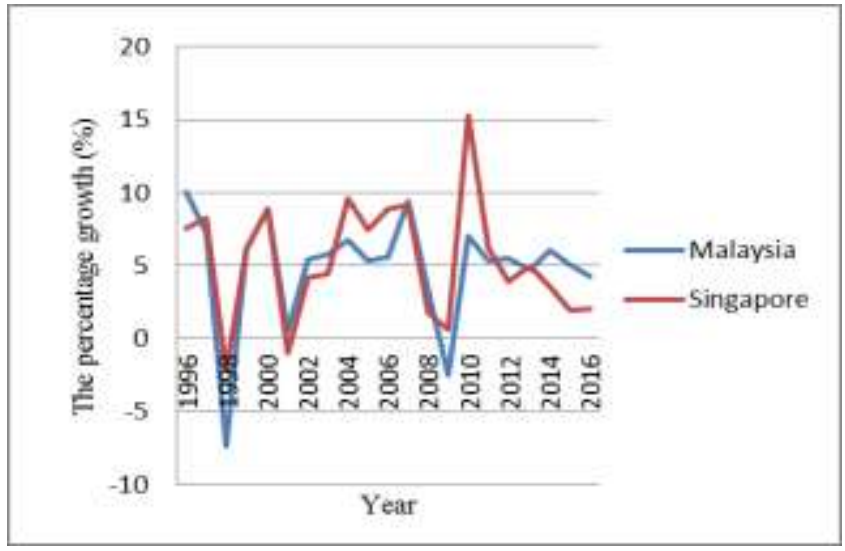

Fig. 2: The distribution of economics growth in Malaysia and Singapore from 1996 until 2016

\subsection{Statistical Analysis}

The study showed that the population values in the Malaysia and Singapore was positively correlated but not significantly to the rate of economic growth $\left(R^{2}=0.016\right.$ and $\left.R^{2}=0.002\right)$ (Figure 3 ). These results indicate that the level of population level is not the main contributing factors for economic growth. Economic growth can be defined as a positive change in the level of goods and services produced by a country over a certain period of time. So, the economic growth is never uniform or same in all sectors of an economy especially in developed and developing countries. According economics theory said as the population increases in size, the demand for consumer goods and services continues to increase as does the national productivity rate. From the regression relationship for Malaysia (developing country) and Singapore (developed country) proved if gross domestic product, or GDP, growth 
doesn't keep up with population growth, then GDP on a per capita basis declines. That is because on average, each citizen would generate less economic value. As a result, the country becomes relatively poorer. For this reason, it is important that GDP growth outpaces population growth. Besides that, the economists measure output in terms of revenues and gross domestic product, among other things. Input is measured by factors such as the workforce or invested capital. Generally speaking, economists associate higher national productivity levels with a greater degree of wealth creation in that country. When unemployment rises, on the other hand productivity ultimately lags as the workforce loses skills and becomes idle.

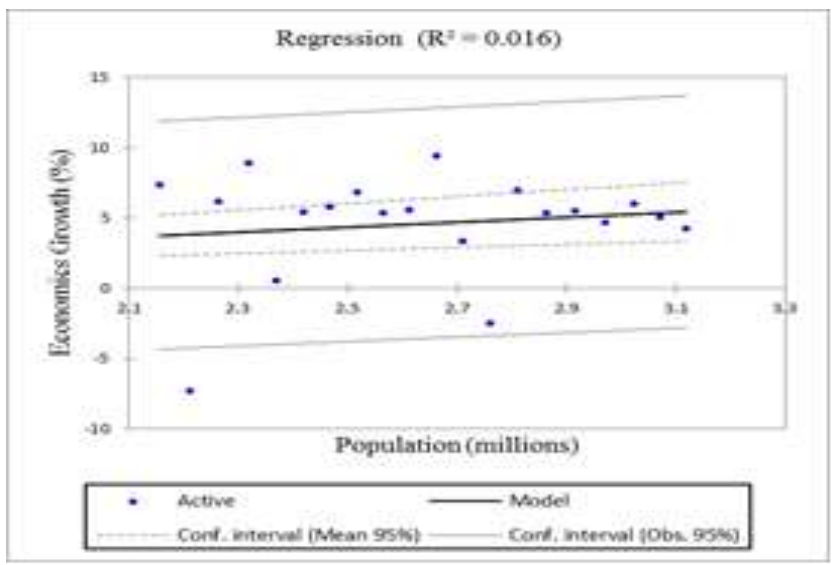

(a)

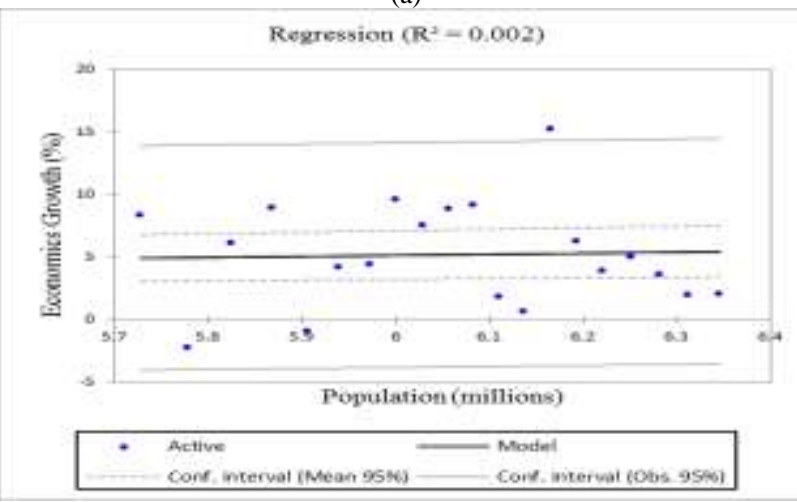

(b)

Fig. 3 (a) (b): The regression relationship between distribution of population and economics growth in Malaysia and Singapore from 1996 until 2016

The CA dendogram (Figure 4 (a) (b) and Figure 5 (a) (b)) showing different clusters of states based on economic growth in Malaysia and Singapore from 1996 until 2016. From spatial classification of economic growth pattern shows six different spatially patterns for Malaysia and five differently spatially pattern for Singapore along 10 years. From Figure 4 (b) showed Cluster 1 consists of 11 years (1997, 1999, 2002, 2003, 2004, 2005, 2006, 2011, 2012, 2013 and 2014), Cluster 2 consist only one year (1998), Cluster 3 consists of two years (2000 and 2007), Cluster 4 consist only one year (2001), Cluster 5 consists 3 years $(2008,2015$ and 2016) and Cluster 6 consist only one year (2009). From clustering analysis showed the economic trends of Malaysia with not equilibrium within 10 years because has become an upper-middle-income country that hopes to attract additional investments in value-added production of high technology, knowledge-based goods, and services. To enhance competitiveness, the government has liberalized some services subsectors and adopted fiscal reforms to achieve a balanced budget by 2020 through tax reform and reduced subsidies. The trade regime is relatively open. There is no mandated minimum wage, and labour regulations are not rigid. The judicial system's vulnerability to political influence is a significant challenge to the rule of law. This classification reflected the multifaceted aspect of development, consideration could also be given to constructing compo- site indices of various economic and social indicators. The criterion for inclusion into the category of countries in transition was that the country in question was in a "transitional state of their economies from an administered system to one based on market principles.

Table 2: Class classification details using Cluster Analysis (CA) Dendogram

\begin{tabular}{|c|c|c|}
\hline $\begin{array}{c}\text { Class } \\
\text { Classification }\end{array}$ & $\begin{array}{c}\text { Year } \\
\text { (Malaysia) }\end{array}$ & $\begin{array}{c}\text { Year } \\
\text { (Singapore) }\end{array}$ \\
\hline Class 1 & $1997,1999,2002$, & $1996,1997,1999,2002$, \\
& $2003,2004,2005$, \\
& $\begin{array}{c}2006,2011,2012, \\
2013 \& 2014\end{array}$ & $2007,2004,2005,2006 \&$ \\
& 1998 & $1998 \& 2001$ \\
\hline Class 2 & $2000 \& 2007$ & 2010 \\
\hline Class 3 & 2001 & $2011,2012,2013,2014$, \\
\hline Class 4 & $2008,2015 \& 2016$ & $2015 \& 2016$ \\
\hline Class 5 & & 2009 \\
\hline Class 6 & & \\
\hline
\end{tabular}

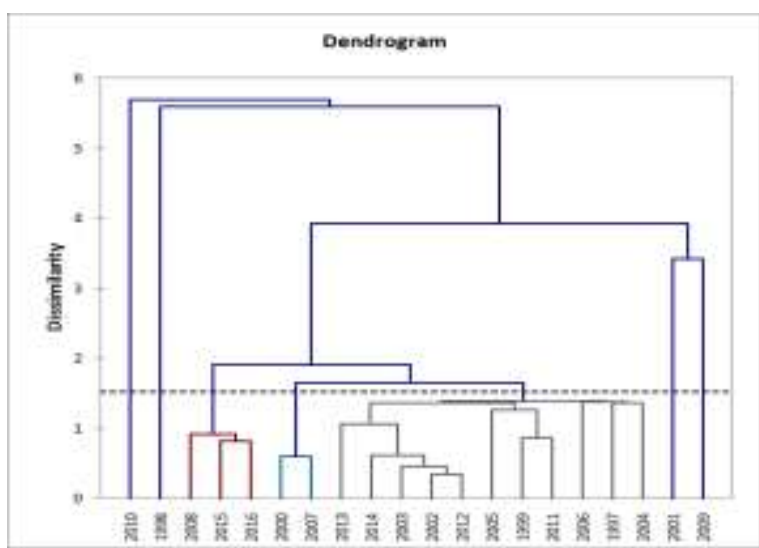

(a)

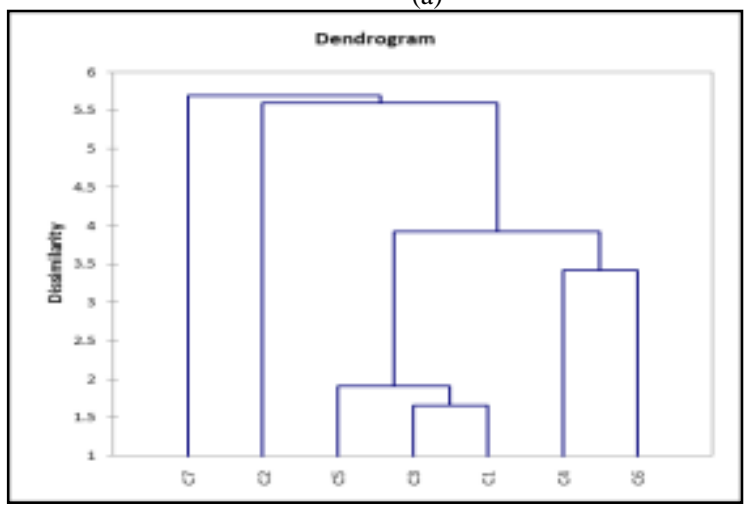

(b)

Fig. 4 (a) (b): Dendogram showing different clusters of states based on economic growth in Malaysia from 1996 until 2016

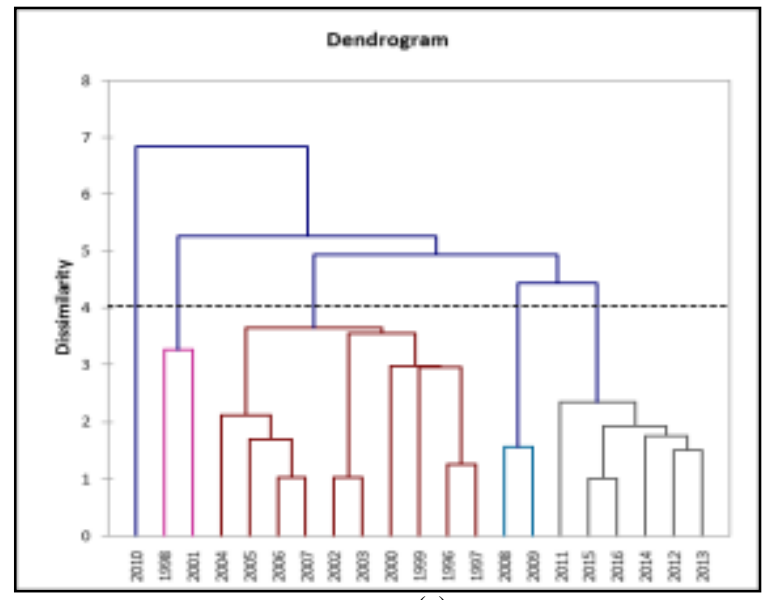




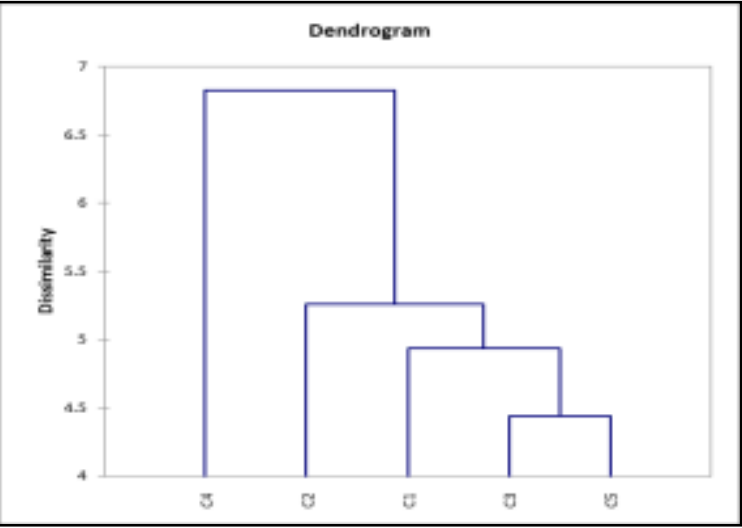

(b)

Fig. 5 (a) (b): Dendogram showing different clusters of states based on economic growth in Singapore from 1996 until 2016

\section{Conclusion}

The relationship between population growth and economic development has been a recurrent theme in economic analysis. The high population growth creates pressures on limited natural resources, reduces private and public capital formation, and diverts additions to capital resources to maintaining rather than increasing the stock of capital per worker. The positive effects such as economies of scale and specialization, the possible spur to favorable motivation caused by increased dependency. Much of the motivation for human capital policies in developing countries is the possibility of providing economic growth that will raise the levels of incomes in these countries. The focus on alleviating poverty in developing countries relates directly to economic growth because of the realization that simply redistributing incomes and resources will not lead to long run solutions to poverty.

\section{Acknowledgement}

The authors acknowledgment to UniSZA and MOHE for scholarship under research grants: (UniSZA/2017/SRGS/17) - R0019R017, (FRGS/1/2017/WAB05/UNISZA/01/1) - RR22 and RAGS $/ 1 / 2015 /$ WAB05 /unisza /02 /1. Special thanks are also dedicated to Fakulti Sains Sosial Gunaan (FSSG), ESERI, UniSZA and Department of Statistics Malaysia give permission to use the research facilities, provided the secondary data and supporting in this research.

\section{References}

[1] Bloom, D., Canning, D., \& Sevilla, J. (2003). The demographic dividend: A new perspective on the economic consequences of population change. Rand Corporation.

[2] Cohen, B. (2006). Urbanization in developing countries: Current trends, future projections, and key challenges for sustainability. Technology in Society, 28(1-2), 63-80.

[3] Dyson, T. (2001). A partial theory of world development: The neglected role of the demographic transition in the shaping of modern society. International Journal of Population Geography, 7(2), 67-90.

[4] Preston, S. H. (1975). The changing relation between mortality and level of economic development. Population Studies, 29(2), 231-248.

[5] Kelley, A. C., \& Schmidt, R. M. (1995). Aggregate population and economic growth correlations: The role of the components of demographic change. Demography, 32(4), 543-555.

[6] Bloom, D. E., Canning, D., \& Sevilla, J. (2004). The effect of health on economic growth: A production function approach. World Development, 32(1), 1-13

[7] Kalemli-Ozcan, S., Ryder, H. E., \& Weil, D. N. (2000). Mortality decline, human capital investment, and economic growth. Journal of Development Economics, 62(1), 1-23.

[8] Kuznets, S. (1955). Economic growth and income inequality. American Economic Review, 45(1), 1-28.
[9] Easterlin, R. A. (1967). Effects of population growth on the economic development of developing countries. Annals of the American Academy of Political and Social Science, 369(1), 98-108.

[10] James, K. S. (2011). India's demographic change: Opportunities and challenges. Science, 333(6042), 576-580.

[11] Coale, A. J., \& Hoover, E. M. (2015). Population growth and economic development. Princeton University Press.

[12] Mitchell, D. J. (2005). The impact of government spending on economic growth. Heritage Foundation, 1813, 1-18.

[13] Anand, S., \& Ravallion, M. (1993). Human development in poor countries: On the role of private incomes and public services. Journal of Economic Perspectives, 7(1), 133-150.

[14] Kamarudin, M. K. A, Toriman, M. E., Sulaiman, N. H., Ata, F. M. Gasim, M. B., Muhamad, A., Yusoff, W. A., Mokhtar, M., Amran, M. A., \& Abd Aziz, N. A (2015). Classification of tropical river using chemometrics technique: Case study in Pahang River Malaysia. Malaysian Journal of Analytical Sciences, 19(5), 10011018.

[15] Wahab, N A., Kamarudin, M K A., Gasim, M B., Umar, R., Ata, F M., \& Sulaiman, N H. (2016). Assessment of total suspended sediment and bed sediment grains in upstream areas of Lata Berangin, Terengganu. International Journal on Advanced Science, Engineering and Information Technology, 6(5), 757-763.

[16] Kamarudin, M. K. A., Toriman, M. E., Wahab, N. A., Juahir, H., Endut, A., Umar, R., \& Gasim, M. B. (2017). Development of stream classification system on tropical areas with statistical approval in Pahang River Basin, Malaysia. Desalination and Water Treatment, 96, 237-254.

[17] Azid, A., Juahir, H., Ezani, E., Toriman, M. E., Endut, A., Rahman, M. N. A., Yunus, K., Kamarudin, M. K. A., Hasnam, C. N. C. Saudi, A. S. M., \& Umar, R. (2015). Identification source of variation on regional impact of air quality pattern using chemometric. Aerosol and Air Quality Research, 15(4), 1545-1558. 